\title{
Description of two new species of Xevioso (Araneae: Phyxelididae) from Southern Africa, with the northernmost localities for the genus
}

\author{
Brogan L. PETT ${ }^{1, *} \&$ Rudy JOCQUÉ ${ }^{2}$ \\ ${ }^{1,2}$ Biodiversity Inventory for Conservation (BINCO), Walmersumstraat 44, 3380 Glabbeek, Belgium. \\ ${ }^{1}$ Colección Científica Para La Tierra, Fundación Para La Tierra, 321 Mariscal Estigarribia, \\ Pilar, Ñeembucú, Paraguay. \\ ${ }^{2}$ Royal Museum for Central Africa, Leuvensesteenweg 13, B-3080 Tervuren, Belgium. \\ *Corresponding author:brogan@paralatierra.org, brogan.pett@outlook.com \\ ${ }^{2}$ Email: rudy.jocque@africamuseum.be \\ ${ }^{1}$ urn:lsid:zoobank.org:author:2EF3744A-3598-4AA2-9436-06177D398D88 \\ ${ }^{2}$ urn:lsid:zoobank.org:author:CF15016C-8CD1-4C9D-9021-44CA7DC7A5D5
}

\begin{abstract}
Two new species of Phyxelididae are described from southern Africa: Xevioso cepfi sp. nov. $(\hat{O}$ ) $)$, from mountains in the Niassa Province of northern Mozambique, and X. megcummingae sp. nov. ( $\delta^{1}+$ ), from urban Harare, northern Zimbabwe and the Viphya Mts in Malawi. They represent the northernmost localities of the genus. An identification key, partially adapted for the new species, is presented. The biogeographical importance of the mountain areas on both sides of the northern part of Lake Malawi is discussed.
\end{abstract}

Keywords. Afromontane, Mozambique, spider, taxonomy, Zimbabwe.

Pett B.L. \& Jocqué R. 2020. Description of two new species of Xevioso (Araneae: Phyxelididae) from Southern Africa, with the northernmost localities for the genus. European Journal of Taxonomy 636: 1-18.

https://doi.org/10.5852/ejt.2020.636

\section{Introduction}

Phyxelididae is a fairly small spider family with 14 genera and only 64 species. It has a peculiar distribution, mainly in southern and eastern Africa and Madagascar, with a few outliers in Turkey and Indonesia. It retained subfamily status in the complete revision by Griswold (1990) but received family status in the study of Griswold et al. (2005).

One of the largest genera, Xevioso Lehtinen, 1967, currently contains nine nominal species (Griswold 1990). Key characteristics of the genus include a well-developed cup-like sclerotized conductor housing a spiral screw-like embolus, unique among the Phyxelididae. The basal embolic sclerite (EBS) can be simple or tripartite, and the tegulum may have a maximum of four processes (see Griswold 1990 for a detailed generic treatment). 
Xevioso was so far restricted to Southern Africa, with one species extending its area into Zimbabwe (X. orthomeles Griswold, 1990) and one (X. jocquei Griswold, 1990) widely separated from the rest in Malawi.

During a BINCO-expedition (see BINCO.eu) in November 2016 to the remote mountains of Chitagal, Sanga and the Njesi Plateau (Niassa Province) in northern Mozambique (Jones et al. 2017), an undescribed species of Xevioso was found. Further evaluation of the Phyxelididae collection in the Royal Museum for Central Africa (RMCA) uncovered a male and female of a second remarkable species from Zimbabwe, with one more specimen from the Viphya Mts in Malawi.

Knowledge on the distribution of the genus is greatly expanded here with the addition of two new species: one in northern Mozambique and another with a remarkable distribution, in northern Zimbabwe and a remote locality in Malawi. Herein, we describe and illustrate these new species and thus provide the northernmost localities for the genus.

\section{Material and methods}

The specimens examined in the current study were preserved in $70 \%$ ethanol and examined using a Nikon SMZ800 stereo microscope for measurements and descriptions. Male palps and female genitalia were drawn with a WILD M10 stereo microscope (Leica). Female epigynes were detached from the abdomen, temporarily mounted in a clearing mixture of methyl salicylate and cedukol (Merck, Darmstadt) and observed with a Leitz Dialux 22 microscope and subject to automontage with the Syncroscopy software. Male palps and habitus were photographed with a Leica MZ16 using the Leica Application Suite (LAS) automontage software (ver. 3.8; Leica, https://leicacamera.com), with a Z-stack of 15-25 images merged into a single photomontage. For SEM photos, specimens were dried overnight in hexamethyldisilazane, gold coated, and examined and photographed with a JEOL $6480 \mathrm{LV}$ scanning electron microscope. Maps were created with the online tool SimpleMappr (Shorthouse 2010). All types are deposited in the Royal Belgian Institute of Natural Sciences (RBINS Brussels, Belgium). Specimens are deposited in the Royal Museum for Central Africa (RMCA, Tervuren, Belgium) and in the Museu de História Natural de Maputo (MHNM, Maputo, Mozambique).

All measurements are given in millimetres $(\mathrm{mm})$.

\begin{tabular}{|c|c|c|}
\hline \multicolumn{3}{|c|}{ Abbreviations (following abbreviations used in Griswold 1990) } \\
\hline ALE & $=$ & anterior lateral eyes \\
\hline AME & $=$ & anterior median eyes \\
\hline $\mathrm{CO}$ & $=$ & copulatory opening \\
\hline $\mathrm{d}$ & $=$ & dorsal \\
\hline DP & $=$ & setose posterodorsal process of male palpal tibia \\
\hline disp & $=$ & dispersed \\
\hline $\mathrm{dw}$ & $=$ & distal whorl \\
\hline EBM & $=$ & median division of EBS \\
\hline EBA 1,2 and 3 & $=$ & mesal, lateral and median branch of tripartite EBS \\
\hline EBS & $=$ & basal embolic sclerite \\
\hline $\mathrm{F}$ & $=$ & femur \\
\hline Mt & $=$ & metatarsus \\
\hline $\mathrm{P}$ & $=$ & patella \\
\hline $\mathrm{PC}$ & $=$ & posterior chamber \\
\hline $\mathrm{pl}$ & $=$ & prolateral \\
\hline PLE & $=$ & posterior lateral eyes \\
\hline PME & $=$ & posterior median eyes \\
\hline
\end{tabular}




$\begin{array}{lll}\mathrm{PML} & = & \text { posterior median lobe of epigyne } \\ \mathrm{rl} & = & \text { retrolateral } \\ \mathrm{TA} 2 & = & \text { central tegular process } \\ \mathrm{TA} 3 & = & \text { retrolateral tegular process } \\ \mathrm{T} & = & \text { tibia } \\ \mathrm{t} & = & \text { tarsus } \\ \mathrm{TL} & = & \text { total length }\end{array}$

\title{
Results
}

Taxonomy

\author{
Class Arachnida Cuvier, 1812 \\ Order Araneae Clerck, 1757 \\ Family Phyxelididae Lehtinen, 1967 \\ Genus Xevioso Lehtinen, 1967 \\ Xevioso cepfi sp. nov. \\ urn:1sid:zoobank.org:act:500CF91F-7D90-466F-88F3-1E48938DF676
}

Figs $1-3,4 \mathrm{~A}, \mathrm{D}, 5,8$

\section{Diagnosis}

Males of $X$. cepfi sp. nov. can be recognized by the axel-shaped, dark dorsal asetose process of the palpal T, which is thin and transparent in $X$. jocquei, combined with the pronounced, blunt DP (Figs $1 \mathrm{C}$, 3B-C, 4A) and the palpal bulb with sharp bifid tegular process on TA3 which is shorter and blunt in $X$. jocquei. Females are characterized by the double coil of the copulatory duct, the anterior median duct of the spermathecae being almost twice as large as the posterolateral duct, also the anterior median duct converging centrally and almost touching (Fig. 5B-C).

\section{Etymology}

Named after the Critical Ecosystem Partnership Fund (CEPF), funders of the Njesi BINCO expedition, during which this species was discovered.

\section{Material examined}

\section{Holotype}

MOZAMBIQUE • ${ }^{\Uparrow}$; Niassa Region, Sanga Plateau; $12^{\circ} 22.580$ S, $35^{\circ} 20.013$ E; 1724 m a.s.1.; 18 Nov. 2016; L. Geeraert and M. Jocqué leg.; forest; pitfall with fence; RMCA_ARA_245493.

\section{Paratypes}

MOZAMBIQUE • 1 \%; Niassa Region, Sanga Plateau; $12^{\circ} 22.5802$ S; $35^{\circ} 20.0132$ E; 1724 m a.s.l.;

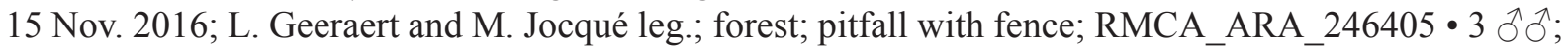

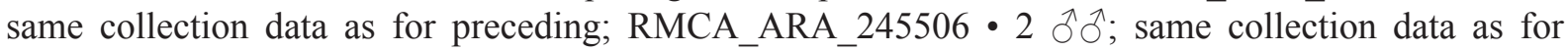
preceding; MHNM • 1 क; Niassa Region, Sanga Plateau; $12^{\circ} 24.007^{\prime}$ S, 35²0.070' E; 16 Nov. 2016; L. Geeraert and M. Jocqué leg.; montane forest; pitfall with fence; RMCA_ARA_245496 2 ô $\widehat{\delta}$; Niassa Region, Chitagal Plateau; $12^{\circ} 35.4952 \mathrm{~S}, 35^{\circ} 15.1342 \mathrm{E}, 1624 \mathrm{~m}$ a.s.l.; Nov. 2016; montane forest; pitfall for herpetology; L. Geeraert and M. Jocqué leg. RMCA_ARA_245487.

\section{Other material}

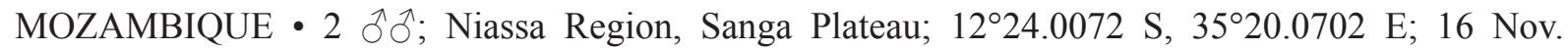
2016; montane forest; L. Geeraert and M. Jocqué leg.; pitfall for herpetology; RMCA_ARA_246548

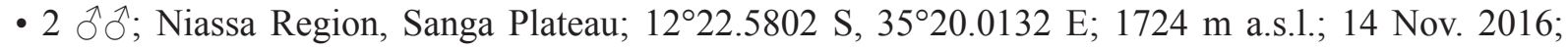


forest; pitfall; L. Geeraert and M. Jocqué leg.; RMCA_ARA_246550 • 1 ô; same collection data as for preceding; RMCA_ARA_246551 - 2 ôं; same collection data as for preceding; 18 Nov. 2016;

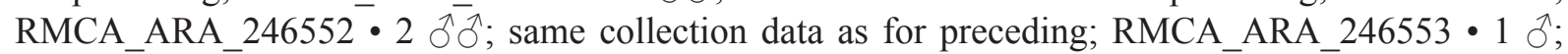
Niassa Region, Chitagal Plateau; 12³5.495' S, 35¹5.134' E; 1624 m a.s.1.; 8 Nov. 2016; L. Geeraert and M. Jocqué leg.; montane forest; pitfall; RMCA_ARA_246554 • 1 đ; same collection data as for

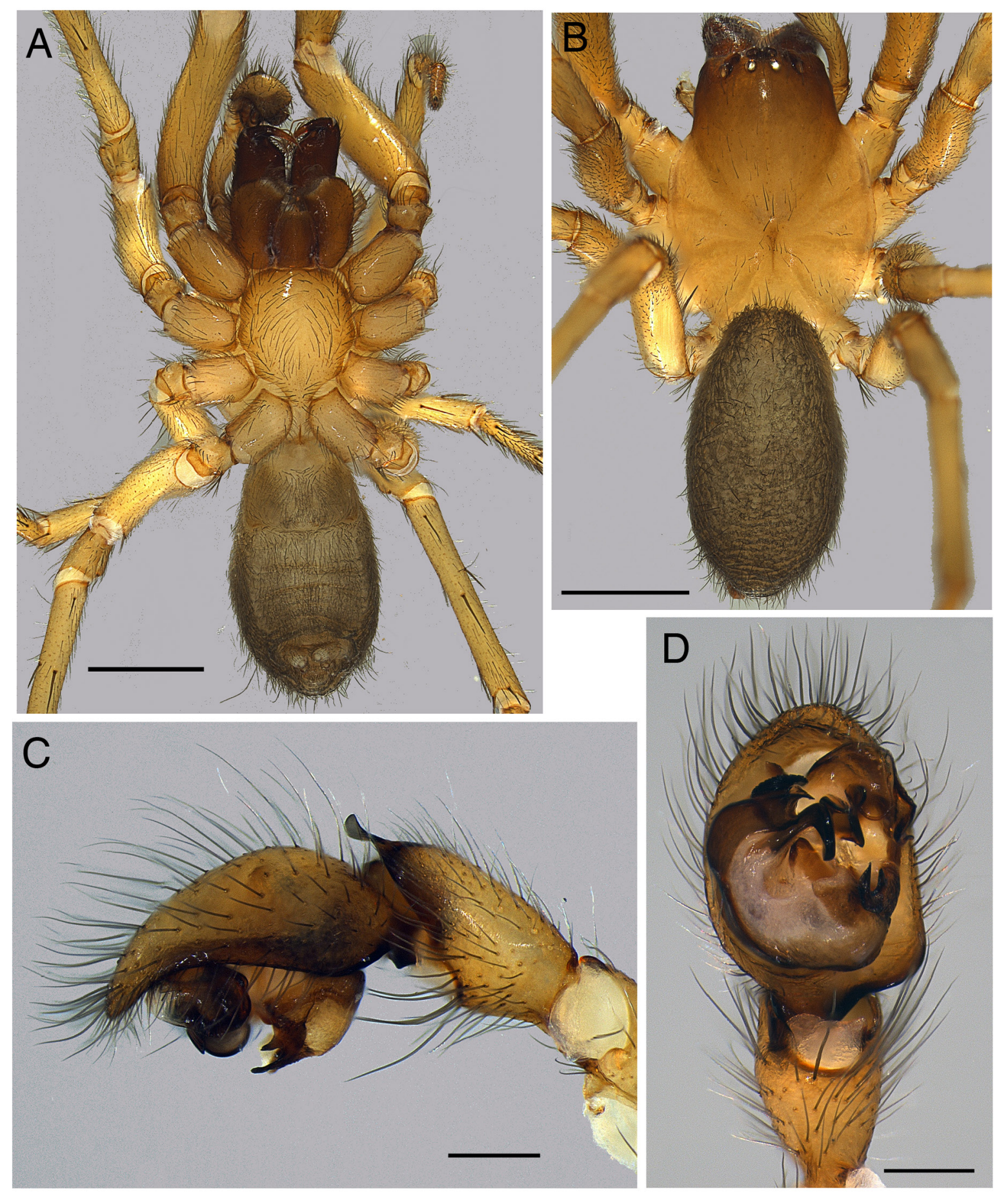

Fig. 1. Xevioso cepf $i$ sp. nov., holotype, ổ (RMCA_ARA_245493). A. Habitus, ventral view. B. Habitus, dorsal view. C. Palp, retrolateral view. D. Palp, ventral view. Scale bars: A-B =1 mm; C-D = $200 \mu \mathrm{m}$. 

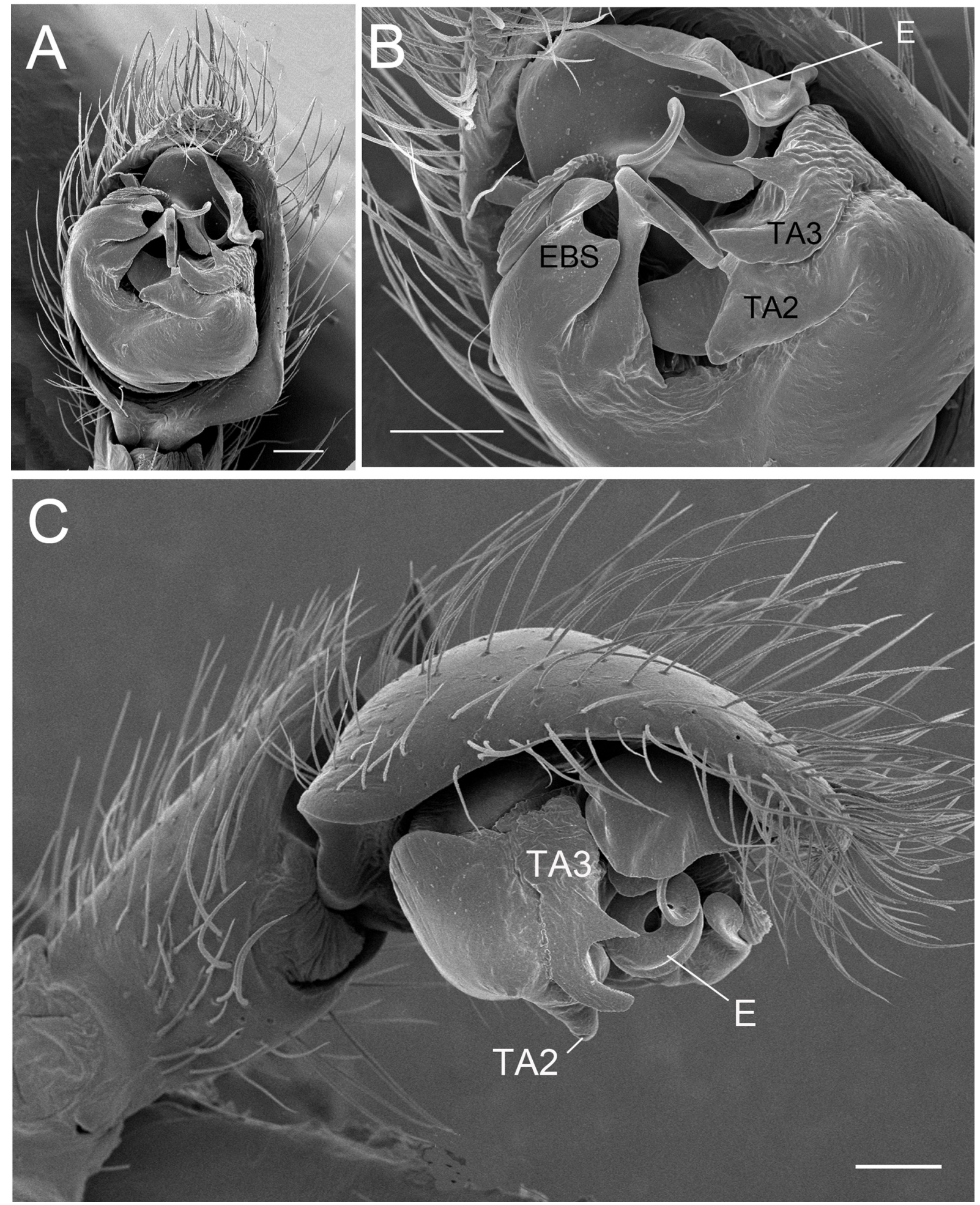

Fig. 2. Xevioso cepfi sp. nov., Ô, paratype (RMCA_ARA_245487). A. Palp, ventral view. B. Palp, as preceding, detail. C. Palp, retrolateral view. Abbreviations: EBS = basal embolic sclerite; E = embolus; TA2, TA3 $=$ tegular apophyses 2 and 3 . Scale bars $=100 \mu \mathrm{m}$. 
preceding; RMCA_ARA_246549 •1 ${ }^{\lambda}$; same collection data as for preceding; 11 Nov. 2016; RMCA

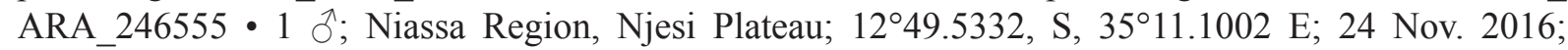
L. Geeraert and M. Jocqué leg.; montane forest; pitfall with fence; RMCA_ARA_246556.

\section{Description}

\section{Male holotype}

Total Length. 4.60. Carapace: length 2.15, width 1.68, height 1.63.

Colour (Fig. 1A-B). Carapace light yellowish-brown, lighter posteriorly, shading to dark brownishorange at pars cephalica, blackened around eyes and between AME. Co and Tr concolorous with posterior region of carapace, remainder of legs darkened to pale brownish-orange at tip of each metatarsus. Chelicerae darkest part of body, dark red-brown, with clypeus orange-brown. Sternum cream yellow. Dorsum of abdomen grey, venter pale grey, with some paler areas, pedicel concolorous with sternum.

CARAPACE. Margins weakly sinuate, with very sparse short setae. Carapace with highest point in cephalic area, 1.5 times higher than at fovea (1.63 vs 1.04$)$.

Eyes. ALE 0.11; AME 0.10; PLE 0.06; PME 0.06; ALE-AME 0.05; AME-AME 0.03; PME-PME 0.12.

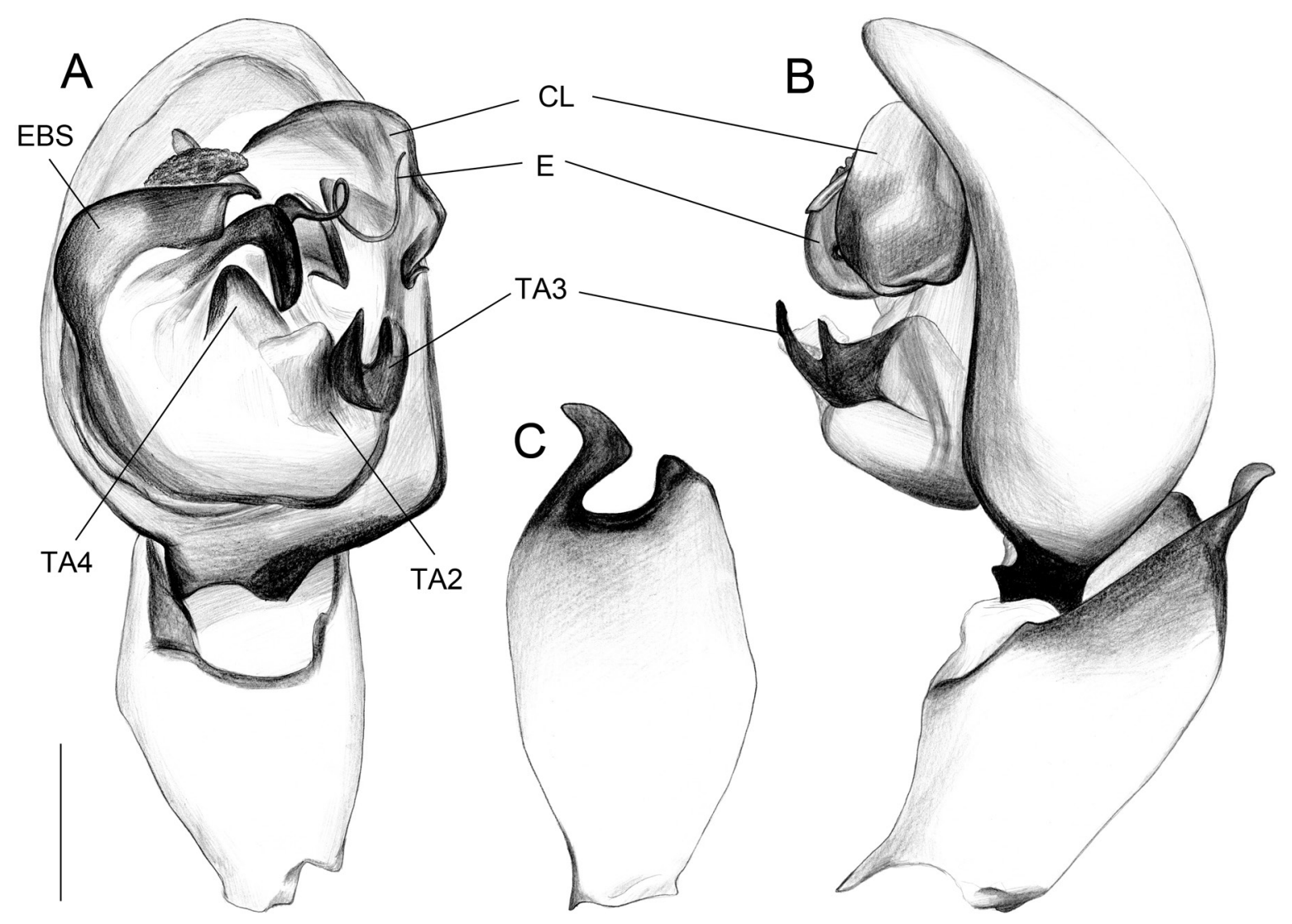

Fig. 3. Xevioso cepfi sp. nov., holotype, $\widehat{O}$ (RMCA_ARA_245493). A. Palp, ventral view. B. Palp, retrolateral view. C. Palpal tibia, dorsal view. Abbreviations: $\mathrm{EBS}=$ basal embolic sclerite; $\mathrm{E}=$ embolus; $\mathrm{CL}=$ lateral ridge of conductor; TA2, TA3, TA4 $=$ tegular apophyses 2, 3 and 4. Scale bars $=200 \mu \mathrm{m}$. 
Chelicerae. Promargin with six teeth, three smallest distally and three larger proximally, with the median of the larger teeth being largest. Retromargin with four small and one large tooth.

AвDOMEN. With short black setae, denser laterally and longest at posterior apex. Venter with dispersed setae, longest at posterior apex.

LEGS. Formula 1423, F I thicker, weakly undulated. P with small but distinct retrolateral process/ protrusion. Mt I with very weak pl concavity $2 / 3$ towards apex (fig. 4D).

LEG MEASUREMENTS.

\begin{tabular}{lcccccc} 
& F & P & T & Mt & t & Total \\
\hline I & 2.52 & 0.88 & 2.24 & 2.04 & 0.87 & 8.55 \\
II & 1.88 & 0.72 & 1.52 & 1.42 & 0.84 & 6.38 \\
III & 1.68 & 0.68 & 1.24 & 1.32 & 0.75 & 5.67 \\
IV & 2.16 & 0.64 & 2.08 & 1.81 & 0.80 & 7.49
\end{tabular}

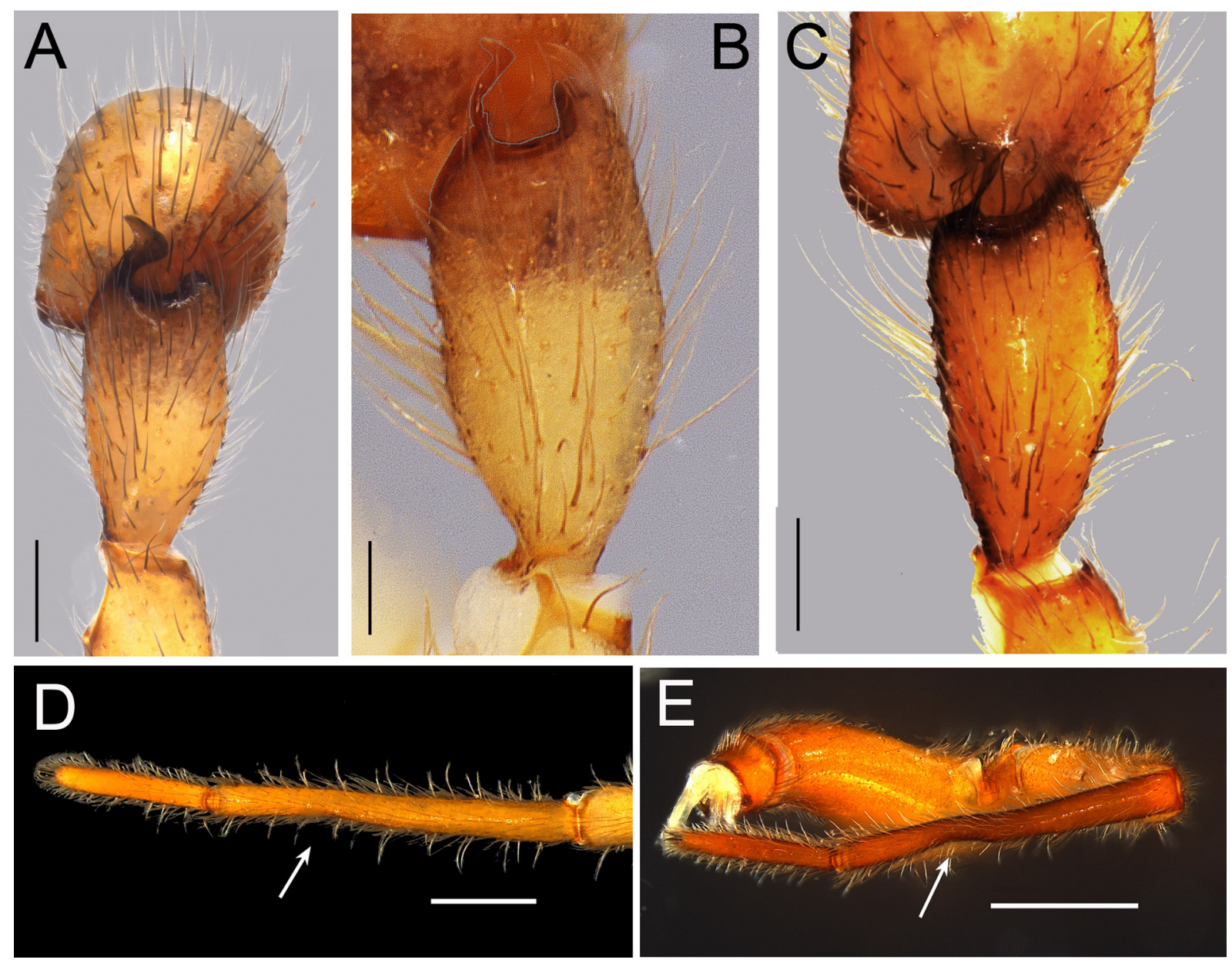

Fig. 4. A, D. Xevioso cepfi sp. nov., holotype, ô (RMCA_ARA_245493). B, E. Xevioso jocquei Griswold, 1990, holotype, $\widehat{\jmath}$ (RMCA_ARA_156494). C. Xevioso megcummingae sp. nov., holotype, $\widehat{\partial}$ (RMCA ARA_236654). A-C. Palpal tibia, dorsal view. D-E. Mt I, dorsal view. Scale bars: A $=200 \mu \mathrm{m}$; B-C = $100 \mu \mathrm{m} ; \mathrm{D}-\mathrm{E}=0.5 \mathrm{~mm}$. 
Sination. Leg I: F = p11, T=v3, Mt = v4; Leg II: F = pl1, T=pl1 v2, Mt = pl1 rl1 v3; Leg III: T= pl2 rl2 v2; Leg IV: T = p11 d2 r11 v3.

Sternum (Fig. 1A). 1.2 long, 0.92 wide. Shield-shaped, with slightly sinuous lateral margins. Black setae longer at margins and without setae centrally. No precoxal sclerites.

Palp (Figs 1C-D, 2A-C, 3A-C, 4A). F with two short stout anterobasal thorns. T with strong, dark axle-shaped process and pronounced DP, delimiting concavity with narrow opening. Palpal bulb simple, not divided into basal and retrobasal lobes. Embolus broadest at base but tapered apically into slender corkscrew, with three coils. TA3 with two acutely pointed prongs, TA2 lobate with short, blunt tip. EBS tri-partite, EBA1 sub-quadrate with weak posterior point, EBA2 recurved and slender, EBA3 fine and serrated with apex curving dorsally. Conductor with $\mathrm{rl}$ transverse ridge, basocentral lobe distad of embolus, and lateral and apical fringe.

\section{Female paratype}

Total Length. 4.45. Carapace length 2.04. Carapace width 1.45. Carapace height 1.12.
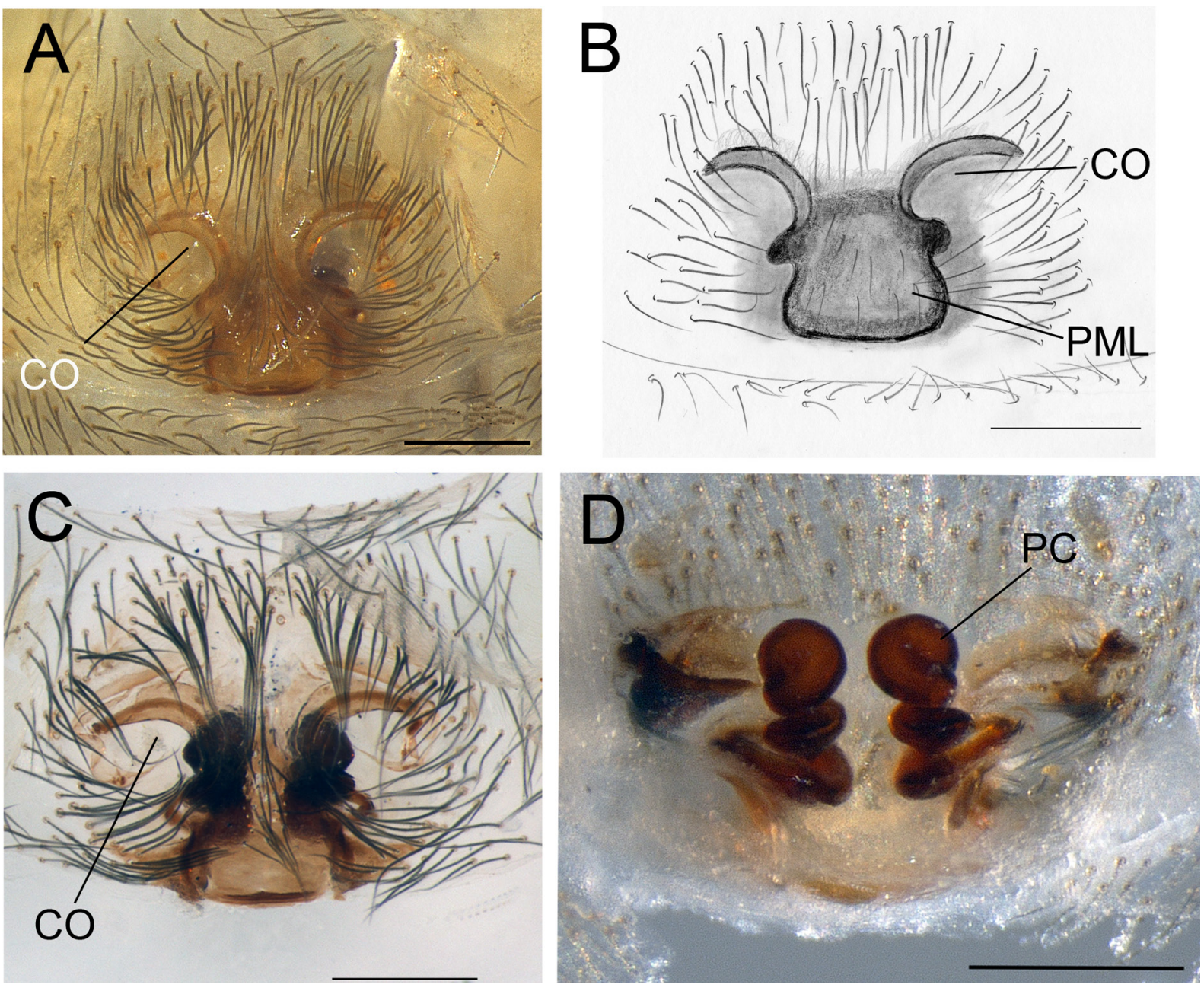

Fig. 5. Xevioso cepfi sp. nov., +, paratype (RMCA_ARA_245496), epigyne. A-B. Ventral view. C. Cleared, ventral view. D. Cleared, dorsal view. Abbreviations: $\mathrm{CO}=$ copulatory opening; $\mathrm{PC}=$ posterior chamber; $\mathrm{PML}=$ posterior median lobe. Scale bars $=200 \mu \mathrm{m}$. 
Colour. Carapace uniform, creamy yellow-brown. Clypeus from AME's darker, orange-brown, thin line around margin of clypeus black. Chelicerae substantially darker, a deep reddish brown. Legs concolorous with carapace, except leg I: darkening at Mt a deep orange. Abdomen grey with short black setae, venter paler grey, creamy at anterior margin with pedicel concolorous with carapace base.

CARAPACE. Margins very weakly sinuate, if at all. Sparse black setae reach highest abundance medially, anterior of the fovea.

Eyes. ALE 0.08; AME 0.09; PLE 0.07; PME 0.06; ALE-AME 0.06; AME-AME 0.04; PME-PME 0.12

Chelicerae. Promargin with four teeth, retromargin with six small teeth

АвDомEN. Venter light grey to cream at anterior, with short black setae uniform throughout, getting only marginally longer at the posterior end.

LeGs. Formula 143? (missing leg II). F I undulates weakly $2 / 3$ of length toward apex. As in males, distinct but small $\mathrm{rl}$ process/ protrusion at pa. Females lack pl concavity at the $\mathrm{mt}$ present in males.

LEG MEASUREMENTS.

\begin{tabular}{lcccccc} 
& F & P & T & Mt & t & Total \\
\hline I & 1.73 & 0.72 & 1.60 & 1.34 & 1.01 & 6.40 \\
II & - & - & - & - & - & - \\
III & 1.40 & 0.57 & 0.93 & 0.91 & 0.63 & 4.44 \\
IV & 1.67 & 0.73 & 1.58 & 1.48 & 0.83 & 6.29
\end{tabular}

Spination. Leg I: F = p11, T=v1, Mt = v3; Leg III: F = pl2 rl1 v1, Mt = 3disp, 4dw; Leg IV: T= r11 v1, $\mathrm{Mt}=4 \mathrm{disp}, 4 \mathrm{dw}$.

STERnUm. Roughly shield-shaped, straight at anterior margin. Black setae at margins but without setae centrally. 1.10 long and 0.94 wide.

Epigyne (Fig. 5A-D). Posterior median lobe of epigyne twice as wide as long, widest at lateral midpoint. Vulva with spermathecae cylindrical, with external spiral of three turns. Anterior median duct of spermathecae converge slightly at anterior apex, towards touching from lateral. Dorsal posterior chambers face laterally.

Xevioso megcummingae sp. nov. urn:lsid:zoobank.org:act:DD398E33-4DA0-45C2-9079-B009CD955541

Figs 4C, 6-8

\section{Diagnosis}

Males of X. cummingae sp. nov. can be distinguished from others in the genus by the following character combination: (1) Mt I modified, with strong and broad d process $2 / 3$ towards apex, about double the height of Mt apex; (2) palpal T with dorsal hyaline process thin, slightly curved, appearing nail-like in rl view; (3) palpal DP broad and sub-triangular; (4) TA3 tegular processes short and blunt; TA1 absent. Females are recognized by the $\mathrm{CO}$ far apart and the longitudinal axis of the spermathecae diverging anteriad. 


\section{Etymology}

The species name is a matronym in honour of Zimbabwean naturalist, Meg Cumming, collector of the type material.

\section{Material examined}

\section{Holotype}

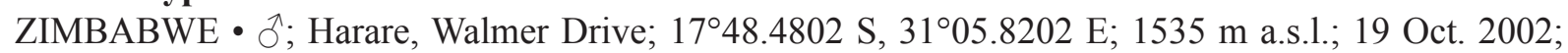
M. Cumming leg.; garden; RMCA_ARA_236654.

\section{Paratype}

ZIMBABWE • 1 \%; same collection data as for holotype; 19 Apr. 2005; RMCA_ARA_236655.

\section{Other material}

MALAWI • 1 今ं; Viphya Plateau, Chikangawa; $11^{\circ} 522$ S, $33^{\circ} 482$ E; 1817 m a.s.l.; Oct. 1977-Feb. 1978; R. Jocqué leg.; young pine plantation; pitfall: RMCA_ARA_153025.

\section{Description}

\section{Male holotype}

Total Length. 6.85. Carapace length 2.92. Carapace width 2.44. Carapace height 1.36.

Colour (Fig. 6A). Carapace light yellowish-orange, darkened anteriorly at pars cephalica, chelicerae deep reddish-brown, darkest part of the body; black pigment around eyes, PME without black pigment, AME's joined by dark pigment. Sternum light yellow, margins darkened to deep reddish-brown. Co and Tr I brownish-orange, darker than others, cream yellow. F I orange, to brownish-orange up to Mt; other legs light brownish-yellow to orange at Mt. Abdomen and venter cream to white entirely.

CARAPACE. Margin weakly sinuate. Short black setae dispersed in irregular and sparse patches. Fovea deeply concave, carapace flat throughout, clypeus height $1.1 \times$ height of carapace at fovea.

Eyes. ALE 0.10; AME 0.10; PLE 0.10; PME 0.08; AME-AME 0.04; PME-PME 0.17.

ABDOMEN. Black setae regularly spaced throughout (both dorsally and ventrally), setae longer posteriorly, reaching 0.4 .

Legs (Fig. 6B-C). Formula 1423, with leg III distinctly shortened. Leg I modified at metatarsus, with strong kink extending dorsally, creating metatarsal process at least twice as high as apical end of metatarsus.

LEG MEASUREMENTS.

\begin{tabular}{lcccccc} 
& F & P & T & Mt & T & Total \\
\hline I & 3.68 & 1.21 & 3.72 & 3.16 & 1.31 & 13.08 \\
II & 2.85 & 1.08 & 2.52 & 2.60 & 1.30 & 10.35 \\
III & 2.68 & 0.91 & 2.18 & 2.28 & 0.93 & 8.98 \\
IV & 3.20 & 1.20 & 3.44 & 3.20 & 1.13 & 12.17
\end{tabular}

Sination. Leg I: $\mathrm{F}=\mathrm{p} 11, \mathrm{~T}=\mathrm{p} 12 \mathrm{r} 11 \mathrm{v} 1, \mathrm{Mt}=\mathrm{p} 12 \mathrm{v} 2 ;$ Leg II: $\mathrm{F}=\mathrm{p} 11, \mathrm{~T}=\mathrm{p} 12 \mathrm{r} 2 \mathrm{v} 5, \mathrm{Mt}=\mathrm{p} 11 \mathrm{~d} 1 \mathrm{r} 14 \mathrm{v}$; Leg III: $\mathrm{F}=$ pl1 d3 rl1, T = d2 rl2 v2, Mt = 3disp 6dw; Leg IV: $F=p 11, T=p 12$ r2 v3, Mt = 2d, 5dw. 

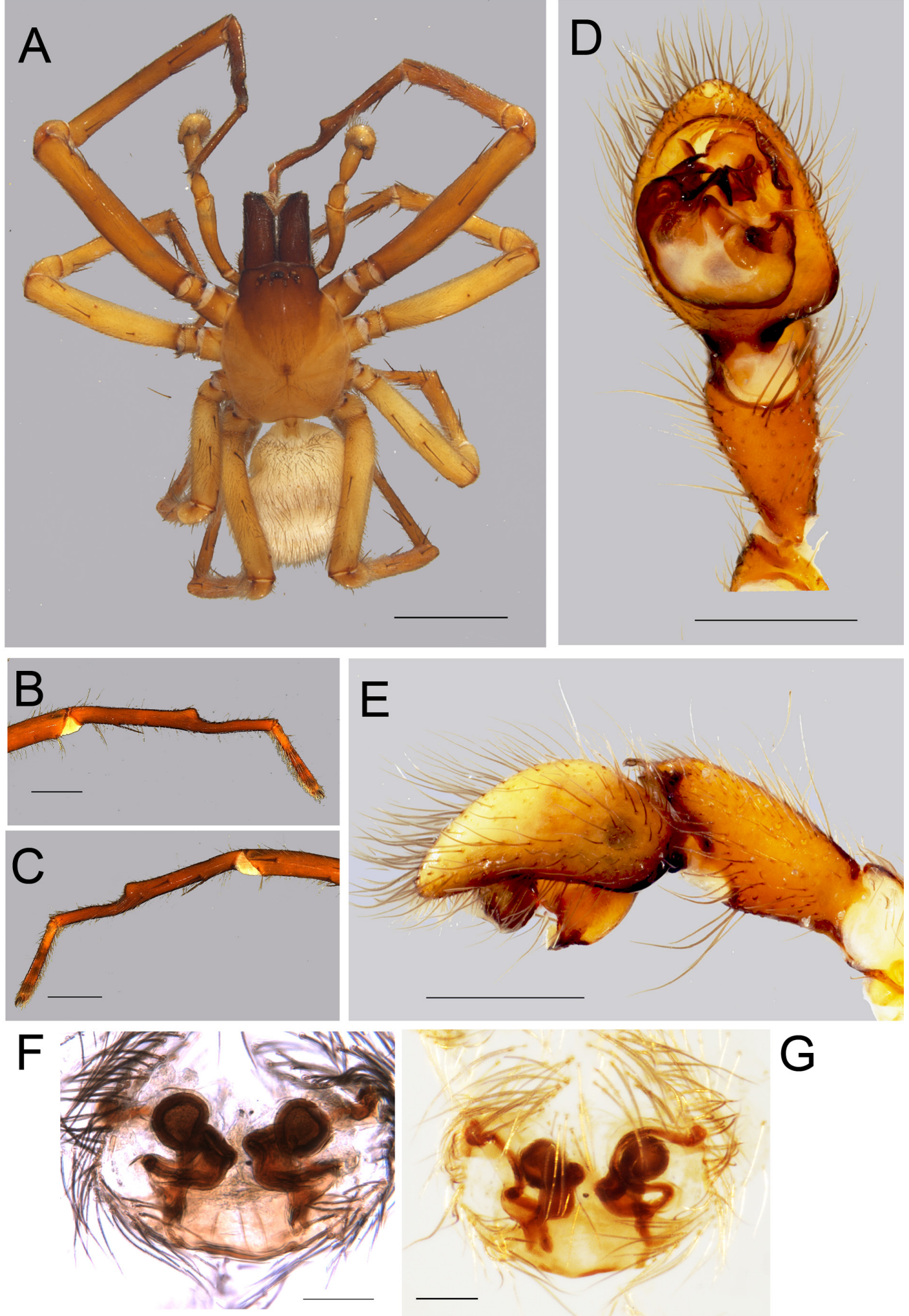

Fig. 6. Xevioso megcummingae sp. nov. A-E. Male holotype (RMCA_ARA_236654). F-G. Male paratype (RMCA_ARA_236655). A. Male habitus, dorsal view. B. MtI, prolateral view. C. MtI, retrolateral view. D. Palp, ventral view. E. Palp, retrolateral view. F. Epigyne, ventral view. G. Epigyne, dorsal view. Scale bars: $A=1 \mathrm{~mm} ; \mathrm{B}-\mathrm{C}=0.5 \mathrm{~mm}$; $\mathrm{D}-\mathrm{E}=200 \mu \mathrm{m} ; \mathrm{F}-\mathrm{G}=100 \mu \mathrm{m}$. 
STERnUm. Roughly oval and distinctly jagged at coxae. 1.61 long and 1.32 wide. Black setae interspersed laterally, with very few medially.

PaLp (Figs 4C, 6D-E, 7A-C). F with dorsal hyaline asetose process slender, curved at extremity, with broad DP delimiting widely open, shallow concavity (Figs 4C, 6E). Embolus turning three times, tapering to acutely pointed corkscrew apex; thickest just before first turn. Tegulum simple, without basal or retrobasal lobes. TA3 with two short, blunt projections; EBS poorly sclerotized, tripartite, EBA1 narrower at apex, almost touching embolus, EBA2 rounded.

\section{Female paratype}

Total Length. 5.18. Carapace length 2.19. Carapace width 1.51. Carapace height 1.30.

Colour. Carapace creamy yellow throughout, darkening to light-orange at clypeus dorsally. Chelicerae boss orange to brown, darkest part of body. Femora lightest, darkening to a deep orange-brown at metatarsi. Abdomen uniform light grey to cream.

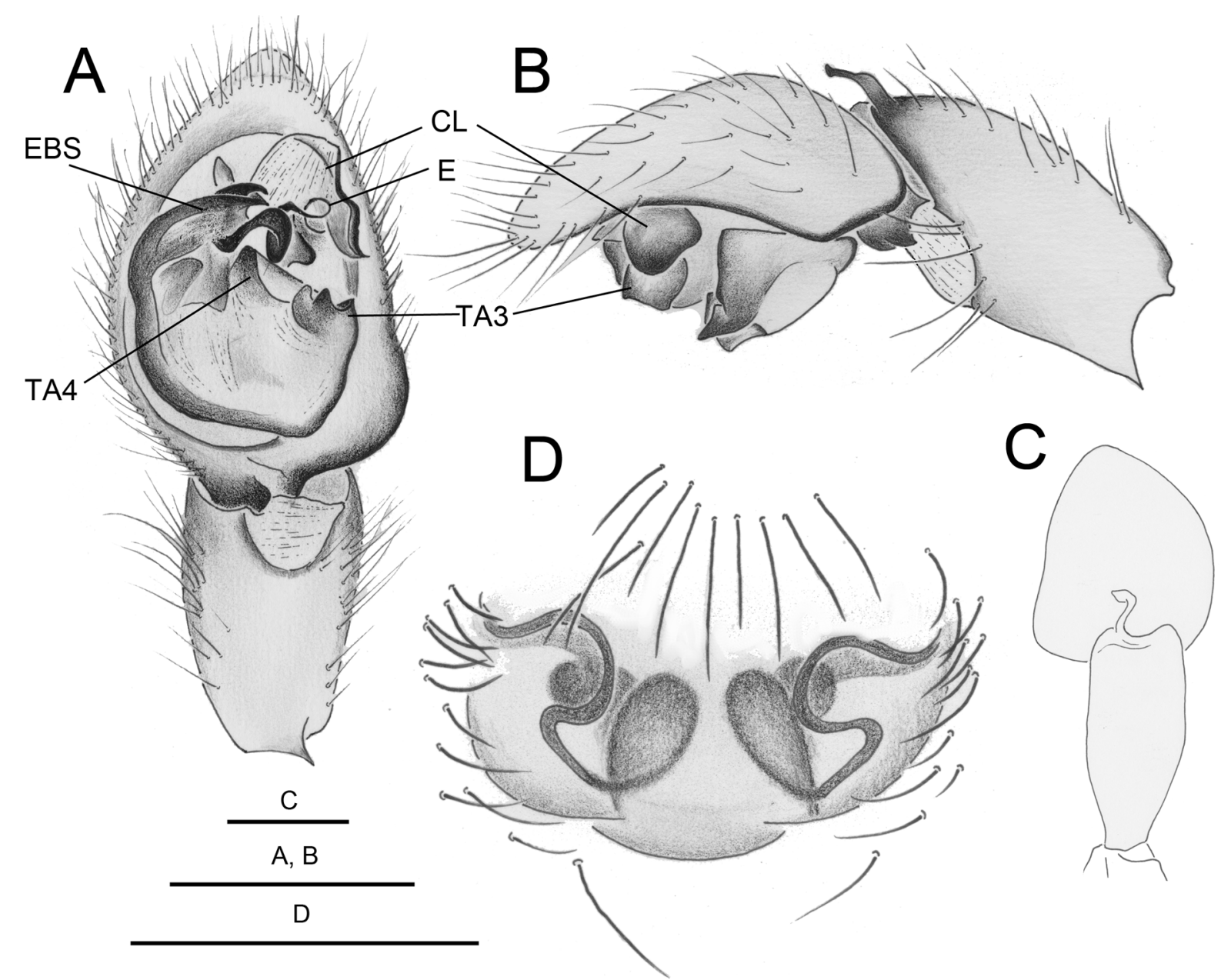

Fig. 7. Xevioso megcummingae sp. nov. A-C. Holotype, $ð$ (RMCA_ARA_236654). D. Paratype, $q$ (RMCA_ARA_236655). A. Palp, ventral view. B. Palp, lateral view. C. Palp, dorsal view. D. Epigyne, ventral view. Abbreviations: $\mathrm{EBS}=$ basal embolic sclerite; $\mathrm{E}=$ embolus; $\mathrm{CL}=$ lateral ridge of conductor; TA3, TA4 $=$ tegular apophyses 3 and 4 . Scale bars: $A-C=500 \mu \mathrm{m} ; \mathrm{D}=100 \mu \mathrm{m}$. 
PETT B.L. \& JOCQUÉ R., Two new species of Xevioso from southern Africa

CARAPACE. Weakly sinuate with short black setae posterior of the fovea. Fovea moderately depressed.

Eyes. ALE 0.07; AME 0.05; PLE 0.04; PME 0.07; ALE-AME 0.08; AME-AME 0.04; PME-PME 0.12

Chelicerae. Strong, 1.30 long, seven teeth present on both promargin and retromargin, promargin with two larger proximal teeth, retromargin all teeth small. Endites with translucent subdecumbent setae.

AвDOMEn. Dorsum with very few setae anteriorly, denser on posterior part. Venter with minimal short fine setae.

LEGS. Formula 123? (legs IV are missing), without pl concavity on metatarsi I as in male.

LEG MEASUREMENTS.

\begin{tabular}{lcccccc} 
& F & P & T & Mt & T & Total \\
\hline I & 2.13 & 0.81 & 1.91 & 1.62 & 0.82 & 7.29 \\
II & 1.81 & 0.66 & 1.37 & 1.20 & 0.71 & 5.75 \\
III & 1.30 & 0.45 & 1.05 & 1.22 & 0.74 & 4.76 \\
IV & - & - & - & - & - & -
\end{tabular}

SpinATIOn. Leg I: F = pl1, T = p12 v3, Mt = pl2 r11 v5; Leg II: F = p11 d1, T= pl2 v1, Mt = p12 rl1 v3; Leg III: $\mathrm{F}=\mathrm{pl} 1 \mathrm{rl1}, \mathrm{T}=\mathrm{pl} 3 \mathrm{~d} 1 \mathrm{rl1} \mathrm{v} 2, \mathrm{Mt}=\operatorname{disp} 3 \mathrm{dw} 4$.

STERnUm. 1.21 long, 0.91 wide. Shield-shaped; with some short black setae.

PALP. With dense procurved setae and toothless claw.

Epigyne (Figs 6F-G, 7D). PML of epigyne wider than long. Copulatory openings far apart, situated on lateral side of epigyne; spermathecae diverging anteriad; fertilization duct leading medially and posteriad from spermathecae.

\section{Variation}

The male specimen from Malawi (RMCA_ARA_153025) is smaller and paler than the holotype. Total length 3.12 (the abdomen has shrunk); carapace length 1.99, width 1.35, height 0.92 .

Xevioso jocquei Griswold, 1990

Figs 4B, E, 8

\section{Material examined}

MALAWI • holotype ${ }^{\wedge}$; Mt Mulanje, Lichenya Plateau; $16^{\circ} 00^{\prime}$ S, 3530' E; 2000 m a.s.1.; 7-23 Nov. 1981; R. Jocqué leg.; seepage area with grassy vegetation; pitfalls; RMCA_ARA_156494.

\section{Key to the species of Xevioso (modified from Griswold 1990)}

Note: figures denoted '*fig.' refer to figures in Griswold (1990).

1. Males

- Females

2. Metatarsus I without dorsomedian projection 3

- Metatarsus I with dorsomedian projection (*figs 33,44$)$ 
3. Tegulum (*fig. 34a) divided into basal lobe and projecting TA3; TA 1 present; apex of EBS simple X. orthomeles Griswold, 1990

- Tegulum (*fig. 46a) simple, without basal lobe, TA3 not protruding; TA1 absent; apex of EBS tripartite

4. Modification of Mt I subtle, hardly discernable (Fig. 4D); TA3 with two sharp prongs (Figs 1C-D, $3 \mathrm{~A}-\mathrm{B}$ ), dorsal apophysis of palpal tibia axe-shaped, delimiting rounded invagination with narrow opening (Figs 1C, 3B-C, 4A) X. cepfi sp. nov.

- Mt I clearly narrowed in center (Fig. 4E); TA3 with blunt prongs; dorsal apophysis of palpal tibia sinuous, delimiting oval invagination with broad opening (Fig. 4B)

X. jocquei Griswold, 1990

5. Tegulum (Figs 6D, 7A) simple, without basal lobe, TA3 not protruding; apex of EBS tripartite): apophysis of palpal tibia sinuous (Figs 4C, 7B-C) delimiting oval invagination with broad opening

X. megcummingae sp. nov.

- Tegulum (*fig. 34a) divided into basal lobe and projecting TA3 6

6. Palpal tibia with no more than 1 elongate apical process, DA unmodified; embolic spiral much narrower than width of cymbium; conductor without hook; metatarsus I with 1 distinct dorsal process

- Palpal tibia with 2 widely separated processes (*fig. $37 \mathrm{~b})$ : an elongate DA and acutely pointed median D process; embolus a broad spiral covering width of cymbium (*fig. 37a); conductor with proximal median hook; metatarsus I with 2 distinct dorsal processes (*fig. 33a)

X. zuluana (Lawrence, 1939)

7. Metatarsus I with an acute dorsal spur (*fig. 40a-d); palpal tibia with DAS produced into a long, sharp point (*fig. 41b); embolus making less than 1 full turn

- Metatarsus I dorsal projection broad and triangular; palpal tibia with DA rounded and unmodified (*fig. 29c); embolus making more than 1 full turn (*fig. 29b)

8. Palpal tibia with hyaline D reduced to a vestige or lost, DAS extending far beyond margin of hyaline D (*fig. 39b); TA3a very long, pointed (*fig. 39c); TA 1 present, slender; proximal margin of conductor transverse, unmodified $(*$ fig. $39 a)$; metatarsus I with fine spinules .......... aululata Griswold, 1990

- Palpal tibia with hyaline D extending for full length of DA, reaching apex of DAS; TA3a short, conical (*fig. 41c); TA1 absent; proximal margin of conductor with an acute, proximad-directed flange (*fig. 41a); metatarsus I with stout spinules

X. colobata Griswold, 1990

9. Palpal tibia with hyaline D broad, margin gently curved or angled (*fig. 45b); apex of EBS bifid (*fig. 42a); embolus with lamella for much of length (*fig. 45a); TAI slender and elongate (*fig. 42c)

- Palpal tibia with hyaline D having a slender median flange (Df) projecting distally (*figs $29 \mathrm{c}, 32 \mathrm{~b}$ ); apex of EBS simple (*fig. 29b); embolus with lamella only at base; TA 1 broad (*figs 29e, 32a) ... 11

10. Conductor with acute proximal flange (*fig. 45c); palpal tibia with hyaline D angled (*fig. 45b) ....

X. kulufa Griswold, 1990

- Conductor without proximal projection (*fig. 42c); palpal tibia with hyaline D evenly curved (*fig. 42b)

X. lichmadina Griswold, 1990

11. Tegulum with TA3a broad, short, conical, apex bifid (*figs 32a, c)

X. tuberculata (Lawrence, 1939)

- Tegulum with TA3a narrow, elongate, apex acutely pointed (*figs 36a, c) .....

X. amica Griswold, 1990 


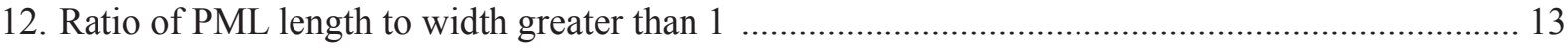

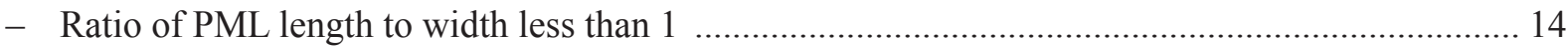

13. Ratio of PML length to width greater than $2(*$ fig. 43a) ..................... lichmadina Griswold, 1990

- Ratio of PML length to width less than $2(*$ fig. 43b) ................................... kulufa Griswold, 1990

14. Epigynum simple, without paired lobes or secondary depressions; copulatory duct small, straight or curved and horn shaped

- Epigynum with paired raised median lobes and shallow paired anterior depressions; copulatory duct very large, spherical, length nearly equal to that of spermathecal capsule $(*$ fig. $38 \mathrm{~b})$

X. zuluana (Lawrence, 1939)

15. Epigynum flat to convex, with lateral margins of PML curved outward posteriorly; spermathecae with spiral duct

- Epigynum with transverse median ridge, lateral margins of PML straight; spermathecae with simple spherical chamber $(*$ figs $12 \mathrm{~d}, 38 \mathrm{c})$

X. aulutata Griswold, 1990

16. Copulatory duct large, hornlike, expanded proximally

- Copulatory duct small, ringlike

17. Diameter of copulatory duct much greater than that of spiral spermathecal chamber $(*$ fig. $35 \mathrm{e}) \ldots \ldots$.

X. amica Griswold, 1990

- Diameter of copulatory duct about equal to that of spiral spermathecal chamber

18. Spiral spermathecal chamber almost touching medially with anterior bulbus spherical spermathecae (Fig. 6F-G). CO far apart

$X$. megcummingae sp. nov.

- Spiral spermathecal chamber not close to touching medially, without bulbus spherical spermathecae head (*fig. 35d)

X. orthomeles Griswold, 1990

19. Spermathecal chamber with 4-5 turns, copulatory duct small and thin (*fig.39f)

X. tuberculata (Lawrence, 1939)

- Epigyne with copulatory opening with distinct sinuation posteriorly (Fig. 5A). Spermathecal chamber with 3 turns (Fig. 5C), copulatory duct expanding widely, wider than spermathecae (Fig. 5B-C) ... X. cepfi sp. nov.

\section{Discussion}

It is well known that the mountain fauna and flora of the South African mountains ranging from the Western Cape in the south-west to the Limpopo Province in the north, are unique and have a high proportion of endemic species (Axelrod \& Raven 1978). The Limpopo appears to be a natural boundary for most of the southern organisms absent in tropical Africa. However, there are a number of elements that are typical of the Cape fauna occurring north of the Limpopo on inselbergs in Malawi and Mozambique, reaching their northernmost limit there. The geological background of this phenomenon is explained in Axelrod \& Raven (1978) and Delvaux (2001). The cedars of the genus Widdringtonia Endl. are an outstanding botanical example, as they reach their northernmost distribution on Mt Mulanje (Malawi) (Pauw \& Lindner 1997), a well-known large inselberg with an altitude of about $3000 \mathrm{~m}$. It harbours numerous representatives of taxa with a southern African distribution (Strugnell 2002). Among these is Sphaerotherium transzambeziacum Jocqué, 1984, a pill millipede belonging to a family that otherwise occurs only south of the Zambezi River (Jocqué 1984). Two more inselbergs at about the same latitude just across the border in Mozambique are Mt Namuli and Mt Mabu, which have been inventoried for invertebrates, but only superficially (Timberlake et al. 2009, 2012). 
It has been questioned whether these inselbergs are the northernmost high-altitude leftovers of a fauna that had a strong connection with the Cape fauna (Jocqué 1983, 1984). The case of Xevioso, which clearly has its center of distribution in eastern South Africa, is interesting in this context. The species $X$. jocque $i$ was considered as an anomaly as far as its distribution is concerned, but it could be explained as a high altitude remnant of a once larger area. It now appears that two more species are found much further north in mountain areas in northern Mozambique and Malawi, on both sides of Lake Malawi, and that the genus has a much larger distribution (Fig. 8). Xevioso cepfi sp. nov. has been collected on all plateaus of the Mozambique Niassa Region at altitudes between 1600 and 1800 m a.s.l. A first hint of the geographic importance of these highlands was already suggested by the inventory of mammals (van Berkel et al. 2019) and reptiles (Bayliss et al. 2014). It has been corroborated by the find of a representative of the genus Cicynethus Simon, 1910 (C. mossambicus Jocqué \& Henrard, 2018), widely separated from C. acer Jocqué \& Henrard, 2018, its nearest relative in South Africa (Jocqué \&

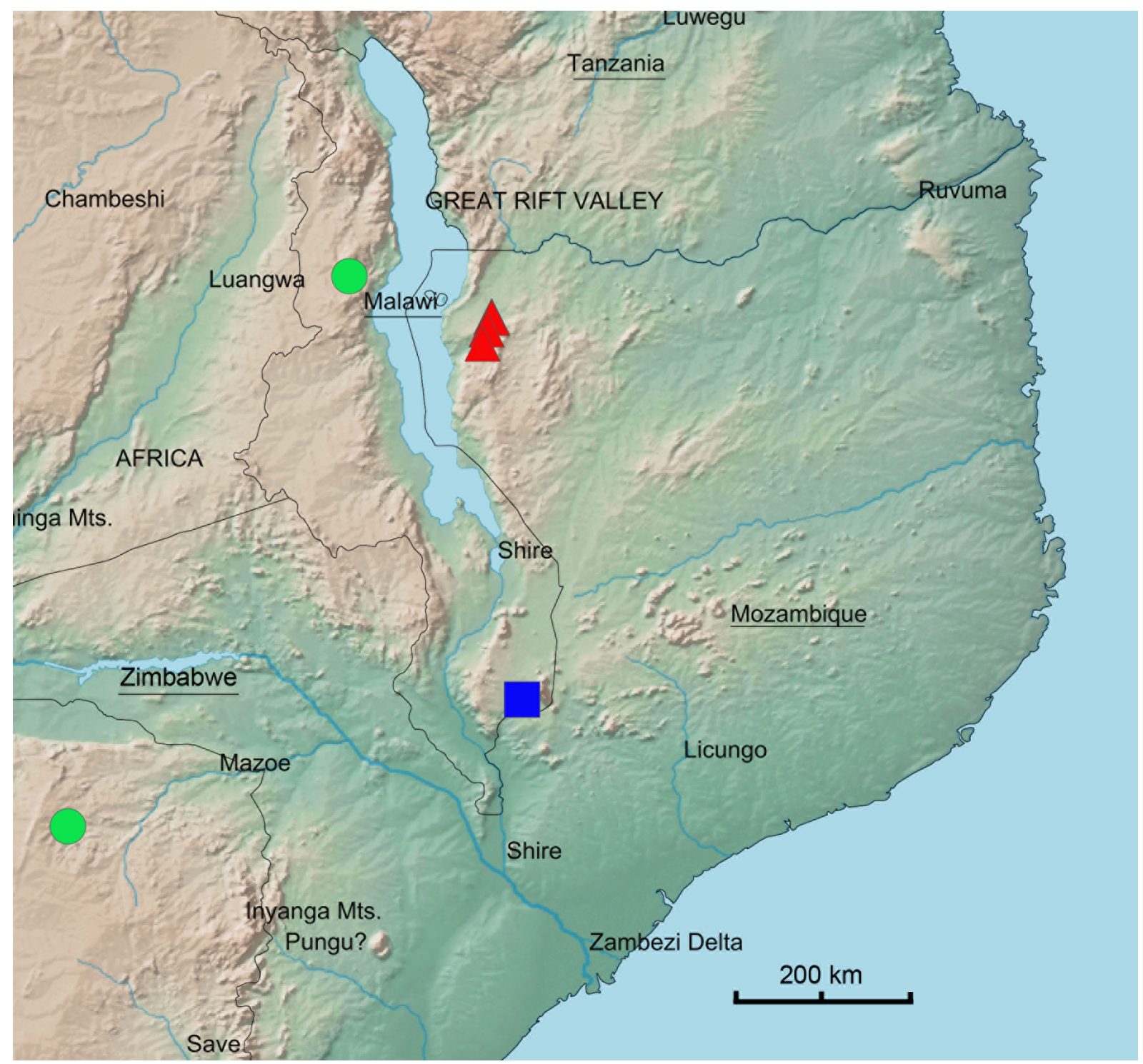

Fig. 8. Distribution. Xevioso cepfi sp. nov. (4), Xevioso jocquei Griswold, 1990 (ロ), Xevioso megcummingae sp. nov. $(\bullet)$. 
Henrard 2018). The find of X. megcummingae sp. nov. at quite a distance from the type locality, shows that the Viphya Mts in Central Malawi may also harbour more interesting endemics.

Our study confirms the importance of these remote altitudinal ranges for the understanding of distribution patterns of southern African taxa with a predilection for montane habitats.

\section{Acknowledgments}

BLP was financially supported by the Systematics Research Fund and Santander Universities Small Project Mobility Fund from Napier University, Edinburgh. The BINCO expedition to Mozambique was supported by the Critical Ecosystem Partnership Fund (Afromontane Hotspots fund), Royal Geographical Society (with IBG) with a Neville Shulman Challenge Award, The Rift Valley Corporation and World Wildlife Fund Belgium. The Critical Ecosystem Partnership Fund is a joint initiative of l'Agence française de Développement, Conservation international, the European Union, the Global Environment Facility, the Government of Japan, MacArthur Foundation and the World Bank. Mozambique material was exported under permit Autorização 12/2016. Thank you to Lucillia Chuquela, Erica Tovela, Pedro Vicente, Simao Manuel and Basidio Buanar for collaboration and help with obtaining the permits. Critical Ecosystem Partnership Fund (CEPF). We also thank kindly Lore Geeraert and Merlijn Jocque for collections made during the Mozambique expedition, and Meg Cumming for collecting and supplying Zimbabwean material. We thank Tony Russell-Smith and an anonymous reviewer for helpful comments on an earlier draft. Hendrik Gheerardyn is thanked for the drawings of the male of $X$. cepfi sp. nov.

\section{References}

Axelrod D.L. \& Raven P.R. 1978. Late Cretaceous and Tertiary vegetation history of Africa. In: Werger M.J.A. (ed.) Biogeography and Ecology of Southern Africa: 77-130. Junk Publishers, The Hague.

van Berkel T., Sumbane E., Jones S.E. \& Jocque M. 2019. A mammal survey of the Serra Jeci Mountain Range, Mozambique, with a review of records from northern Mozambique's inselbergs. African Zoology 54 (1): 31-42. https://doi.org/10.1080/15627020.2019.1583081

Bayliss J., Timberlake J., Branch W., Bruessow C., Collins S., Congdon C., Curran M., de Sousa C., Dowsett R., Dowsett-Lemaire F., Fishpool L., Harris T., Herrmann E., Georgiadis S., Kopp M., Liggitt B., Monadjem A., Patel H., Ribeiro D., Spottiswoode C., Taylor P., Willcock S. \& Smith P. 2014. The discovery, biodiversity and conservation of Mabu forest - the largest medium-altitude rainforest in southern Africa. Oryx 48 (2): 177-185. https://doi.org/10.1017/s0030605313000720

Delvaux D. 2001. Tectonic and palaeostress evolution of the Tanganyika-Rukwa-Malawi rift segment, East African Rift System. Mémoires du Muséum national d'histoire naturelle 186: 545-567.

Griswold C.E. 1990. A revision and phylogenetic analysis of the spider subfamily Phyxelidinae (Araneae, Amaurobiidae). Bulletin of the American Museum of Natural History 196: 1-206.

Griswold C.E., Ramírez M.J., Coddington J.A. \& Platnick N.I. 2005. Atlas of phylogenetic data for entelegyne spiders (Araneae: Araneomorphae: Entelegynae) with comments on their phylogeny. Proceedings of the California Academy of Sciences 56 (Suppl. II): 1-324. Available from https://repository.si.edu/handle/10088/14866 [accessed 27 Mar. 2020].

Jocqué R. 1983. Contributions to the knowledge of the mountain fauna of Malawi (Mission R. Jocqué). 1. Introduction. Revue de Zoologie africaine 97: 185-191.

Jocqué R. 1984. Contributions to the knowledge of the mountain fauna of Malawi (Mission R. Jocqué). 4. Diplopoda Sphaerotheriidae. Revue de Zoologie africaine 98: 67-73. 
Jocqué R. \& Henrard A. 2018. A revision of the genus Cicynethus Simon, 1910 (Araneae, Zodariidae), a tale of colour patterns. European Journal of Taxonomy 465: 1-35. https://doi.org/10.5852/ejt.2018.465

Jones S.E.I., Clause J.K., Geeraert L., Jamie G.A., Patel, H., Sumbane E., van Berkel T. \& Jocque M. 2017. The Njesi Plateau expedition: a biological assessment of Mt Chitagal, Mt Sanga and the Njesi Plateau in Niassa Province, Mozambique. BES Report 6.3 (17 October 2017). Biodiversity Inventory for Conservation. Glabbeek, Belgium.

Pauw C.A. \& Linder H.P. 1997. Tropical African cedars (Widdringtonia, Cupressaceae): systematics, ecology and conservation status. Botanical Journal of the Linnean Society 123: 297-319.

https://doi.org/10.1111/j.1095-8339.1997.tb01421.x

Shorthouse D.P. 2010. SimpleMappr, an online tool to produce publication-quality point maps. Available from http://www.simplemappr.net [accessed 5 Dec. 2019].

Strugnell A.M. 2002. Endemics of Mt. Mulanje. The endemic spermatophytes of Mt. Mulanje. Systematics and Geography of Plants 72: 11-26.

Timberlake J., Dowsett-Lemaire F., Bayliss J., Alves T., Baena S., Bento C., Cook K., Francisco J., Harris T., Smith P. \& De Sousa C. 2009. Mt Namuli Mozambique: Biodiversity and Conservation. Report for Darwin Initiative Award 15/036. Royal Botanic Gardens Kew. Available from

https://www.kew.org/sites/default/files/2019-02/Mt\%20Namuli\%20Mozambique\%20report.pdf [accessed 27 Mar. 2020]

Timberlake J., Bayliss J., Dowsett-Lemaire F., Congdon C., Branch B., Collins S., Curran M., Dowsett R.J., Fishpool L., Francisco J., Harris T., Kopp M. \& De Sousa C. 2012. Mt Mabu Mozambique: Biodiversity and Conservation. Report for Darwin Initiative Award 15/036. Royal Botanic Gardens Kew. Available from https://www.kew.org/sites/default/files/Mabu\%20report_Final\%202012_0.pdf [accessed 27 Mar. 2020].

Manuscript received: 7 January 2020

Manuscript accepted: 9 March 2020

Published on: 28 April 2020

Topic editor: Koen Martens

Desk editor: Pepe Fernández

Printed versions of all papers are also deposited in the libraries of the institutes that are members of the EJT consortium: Muséum national d'histoire naturelle, Paris, France; Meise Botanic Garden, Belgium; Royal Museum for Central Africa, Tervuren, Belgium; Royal Belgian Institute of Natural Sciences, Brussels, Belgium; Natural History Museum of Denmark, Copenhagen, Denmark; Naturalis Biodiversity Center, Leiden, the Netherlands; Museo Nacional de Ciencias Naturales-CSIC, Madrid, Spain; Real Jardín Botánico de Madrid CSIC, Spain; Zoological Research Museum Alexander Koenig, Bonn, Germany; National Museum, Prague, Czech Republic. 